\title{
CORRUPCIÓN Y COLUSIÓN: ASUNTOS DEL SECTOR EMPRESARIAL EN COLOMBIA*
}

\section{Dilia Paola Gómez Patiño**}

Fecha de recibido: 3 de febrero de 2014

Fecha de aprobado: 7 de mayo de 2014

Artículo de Reflexión

Forma de citación: Gómez, D. P. (2014). Corrupción y colusión: asuntos del sector empresarial en Colombia. Revista Prolegómenos. Derechos y Valores, 17, 33, 43-56.

\begin{abstract}
Resumen
La corrupción es uno de los problemas más apremiantes no sólo en Colombia sino en el mundo, por el poder que tiene de quebrantar la democracia y de deslegitimar el papel del Estado frente a los ciudadanos. Es una amenaza para la democracia y el desarrollo económico de la sociedad. Hay múltiples motivos por los cuales la eliminación de la corrupción es prioritaria dentro de la comunidad empresarial: la desconfianza entre inversores, clientes, empleados generada por escándalos éticos; las investigaciones y procesos adelantados por casos de corrupción, entre otros. El sector empresarial, regulado por supuesto por las normas sobre la materia, le apuesta también a mecanismos voluntarios de autorregulación, en un interés por evitar los riesgos reputacionales, que vienen a sumarse a los económicos y legales. El propósito del presente documento es plantear la incidencia de la corrupción en el sector privado, su relación con la colusión, para llegar al marco regulatorio establecido tanto por el Estatuto Anticorrupción como por los compromisos internacionales adquiridos por Colombia. Finalmente, vincula la iniciativa voluntaria de Pacto Global con la participación activa de la ciudadanía.
\end{abstract}

\section{Palabras clave:}

Corrupción, colusión, sector privado, prevención, pacto global, estatuto anticorrupción.

El presente artículo es resultado de investigación dentro del proyecto "Caracterización de la colusión: Una aproximación desde la corrupción", vinculado al grupo de Derecho Público - Categoría B de Colciencias, de la Facultad de Derecho de la Universidad Militar Nueva Granada.

* Abogada CL, Universidad Militar "Nueva Granada", Magíster en Análisis de Problemas Políticos, Económicos e Internacionales, Universidad Externado de Colombia - Instituto de Altos Estudios para el Desarrollo. Integrante del grupo de Derecho Público de la Universidad Militar "Nueva Granada", reconocido en categoría B por Colciencias y al cual se encuentra vinculado el proyecto "Caracterización de la colusión: Una aproximación desde la corrupción". Correo electrónico:diliapg@yahoo.es ódilia.gomez@unimilitar.edu.co 


\title{
CORRUPTION AND COLLUSION: ISSUES OF THE BUSINESS SECTOR IN COLOMBIA.
}

\begin{abstract}
Corruption is one of the most pressing problems not only in Colombia but in the world through the power of democracy, it breaks and delegitimize the role of government to citizens. It is a threat to democracy and economic development of society. There are multiple reasons for the elimination of corruption is a priority within the business community: the mistrust among investors, customers, employees generated by ethical scandals, investigations and proceedings for corruption, among others. The business sector, of course regulated by the rules on the subject, he also committed to voluntary self-regulation, a need to avoid reputational risks, which are in addition to the economic and legal. The purpose of this document is to outline the impact of corruption in the private sector, its relation to collusion, to reach the regulatory framework established by the Anti-Corruption Statute both by the international commitments undertaken by Colombia. Finally, linking the voluntary Global Compact initiative with the active participation of citizens.
\end{abstract}

\section{Key words:}

Corruption, collusion, private sector, prevention, global compact, anticorruption statute.

\section{CORRUPÇÃO E CONSPIRAÇÃO: QUESTÕES DO SETOR DE NEGÓCIOS NA COLÔMBIA}

\begin{abstract}
Resumo
Corrupção estabeleceu a si próprio como um problema premente, não só na Colômbia, mas também no mundo, por causa de seu poder de quebrar democracia e deslegitimar o papel do governo aos cidadãos. É uma ameaça para a democracia e para o desenvolvimento econômico de uma sociedade. Sua ação invalida a disposição fundamental e constitucional da igualdade e gera reações como a subversão, a desigualdade, a desconfiança e instabilidade social, econômica e política. Existem várias razões que tornam a eliminação da corrupção uma prioridade com a comunidade empresarial: desconfiança entre os investidores, clientes e funcionários criados por escândalos éticos, investigações e processos por corrupção, entre outros. Por isso, é cada vez mais necessário chamar a atenção para crimes transnacionais como o suborno, lavagem de dinheiro e enriquecimento ilícito, que foram amplamente ignorados comportamentos por empresas que estão agora mais conscientes da sua responsabilidade pelos atos de seus funcionários, as empresas associadas, parceiros e agentes. O setor empresarial, regulada pelas regras sobre o assunto, também se comprometeu a autoregulação voluntária para evitar riscos de reputação, além dos econômicos e legais.
\end{abstract}

\section{Palavras-Chave:}

Corrupção, Conluio, Setor privado, Prevenção, Pacto global, Anticorrupção estatuto. 


\section{INTRODUCCIÓN}

La corrupción es uno de los problemas más apremiantes no sólo en Colombia sino en el mundo, por el poder que tiene de quebrantar la democracia y de deslegitimar el papel del Estado frente a los ciudadanos. Es una amenaza para la democracia y el desarrollo económico de la sociedad. Su acción invalida el precepto fundamental y constitucional de la igualdad y genera reacciones como la subversión, la inequidad, la desconfianza y la inestabilidad social, económica y política.

En tal sentido, el sector privado, de cara a la realidad del país, adquiere especial relevancia dada la serie de acuerdos comerciales internacionales asumidos por Colombia.

El proyecto se desarrolló como una investigación aplicada de carácter sociojurídico, de tipo correlacional, en la que se aplicó un método deductivo, combinando el método descriptivo-exploratorio y la comparación. En tal sentido, en el presente documento, se partirá de una recopilación de información que permita estructurar los ejes temáticos sobre los cuales elaborar una conclusión posterior.

La autora forma parte de la Red de Pacto Global - Capítulo Colombia- y participa de las mesas de trabajo sobre Derechos Humanos y Anticorrupción de la misma. Esto ha permitido un acercamiento al escenario práctico desde el principio y contribuir tanto a la interlocución como a la generación de actividades que redunden en el logro del mandato del Pacto Global.

Es importante decir que el Pacto Global es una iniciativa internacional y voluntaria propuesta por Naciones Unidas, en la cual las empresas se comprometen a alinear sus estrategias y operaciones con diez principios universalmente aceptados en cuatro áreas temáticas: derechos humanos, estándares laborales, medio ambiente y anti-corrupción; basados en Declaraciones y Convenciones Universales.

Por su número de participantes, varios miles en más de 100 países, el Pacto Global es la iniciativa de ciudadanía corporativa más grande del mundo, Aquellas empresas que se adhieren al Pacto Global comparten la convicción de que las prácticas empresariales basadas en principios universales contribuyen a la construcción de a un mercado global más estable, equitativo e incluyente que fomentan sociedades más prósperas. (En: http://www. pactoglobal-colombia.org/que\%20es.html)

Si bien la mayoría de adheridos provienen del sector privado, también esta abierto a la participación de entidades del sector público y de la academia. Es decir, pretende articular los diferentes actores sociales y constituirse como puente de comunicación entre los mismos, en donde cada uno exponga su visión de los temas que le atañen y se generen acciones conjuntas que redunden en beneficio de la comunidad en general.

El documento inicia planteando la incidencia de la corrupción en el sector privado, luego da paso al fenómeno de la colusión, para llegar al marco regulatorio establecido tanto por el Estatuto Anticorrupción como por los compromisos internacionales adquiridos por Colombia. Finalmente, relaciona la iniciativa voluntaria de Pacto Global con la participación activa de la ciudadanía.

\section{LA CORRUPCIÓN Y EL SECTOR PRIVADO}

Generalmente, las medidas adoptadas para el combate a la corrupción van dirigidas al sector público; no obstante, como lo afirma la directora de la ONG Transparencia por Colombia, Elizabeth Ungar, "el sector privado del país tiene mucha injerencia en los altos niveles de corrupción en el país....En el día a día se piensa que sólo los políticos son corruptos, pero el tema del soborno es algo crítico en el sector privado al igual que la financiación política" (Ungar: 2011)

De acuerdo con los datos suministrados por Doing Bussines 2014, que proporciona una 
medición objetiva de las regulaciones para hacer negocios y su aplicación en 189 economías $y$ en algunas ciudades seleccionadas en el ámbito subnacional, Colombia ocupa el puesto número 43 dentro de la clasificación facilidades para hacer negocios.

Una premisa fundamental de Doing Business es que la actividad económica requiere normas adecuadas, transparentes y accesibles para todos. Las normas deben ser eficientes y lograr un equilibrio entre la preservación de ciertos aspectos importantes del entorno empresarial y la eliminación de distorsiones que impongan un costo desproporcionado sobre las empresas. $\mathrm{Si}$ la regulación empresarial es gravosa y la competencia limitada, el éxito de la iniciativa empresarial depende más de los contactos del emprendedor que de sus capacidades. En cambio, si las regulaciones son fáciles de cumplir y accesibles a todo el que quiera cumplirlas, cualquier persona con talento y buenas ideas puede ser capaz de crear y desarrollar una empresa en el sector formal. (Banco Mundial: 2012)

No obstante, los datos suministrados por la organización no gubernamental Transparencia por Colombia, indican que la corrupción es uno de los factores que más dificultan la realización de negocios para las empresas colombianas; el $31 \%$ de ellas consideran este fenómeno como el segundo problema del país.

Adicionalmente, según Transparencia, el 84,4\% de los empresarios se abstiene de participar en procesos de contratación con el Estado, porque considera que la competencia no es justa, que hay politización en el proceso de contratación y pagos no oficiales. Un $31,74 \%$ de los empresarios afirma que en un proceso de contratación con el Estado, los sobornos son solicitados por los funcionarios públicos y un $16,92 \%$ considera que el empresario interesado es quien los ofrece. Entonces, se estima que el porcentaje promedio a pagar por la obtención de un contrato es del $12.91 \%$ del mismo.

Estas cifras explican por qué hay múltiples motivos por los cuales la eliminación de la corrupción es prioritaria dentro de la comunidad empresarial: la desconfianza entre inversores, clientes, empleados generada por escándalos éticos; las investigaciones y procesos adelantados por casos de corrupción, entre otros. Por eso cada vez es más necesario llamar la atención sobre delitos como el soborno trasnacional, el lavado de activos y el enriquecimiento ilícito; conductas antes casi que ignoradas por las empresas que día a día son más conscientes de su responsabilidad por las acciones del personal, las empresas asociadas, socios y agentes.

Así mismo, la implementación de normas de administración corporativa en todo el mundo también está llevando a las empresas a centrar su atención en medidas anticorrupción como parte de su mecanismo para proteger su reputación y los intereses de sus accionistas. Cada vez aumentan más sus controles internos teniendo en cuenta la ética y la integridad y un número cada vez mayor de gerentes de inversión buscan que estos controles prueben que las empresas están bien manejadas y que existe una buena práctica de los negocios. (Puentes et al: 2006)

Pasó mucho tiempo antes que los costos sociales y económicos de la corrupción fueran considerados relevantes. Hoy hay un mayor entendimiento de su impacto negativo en la sociedad. Las legislaciones internas contemplan en su mayoría el soborno como delito $y$, dadas sus connotaciones, se profirieron instrumentos internacionales para combatir la corrupción en el mundo.

En algunos casos la corrupción tiene tal dimensión e implicaciones que llega a ser sistemática, generalizada. Su erradicación requiere de enormes esfuerzos tanto públicos como privados y de la participación decidida de la ciudadanía.

Las herramientas jurídicas internacionales contra la corrupción son cada vez más preeminentes, pues esto por lo general va ligado a otros fenómenos delictivos transnacionales que conllevan a que los Estados actúen de manera conjunta y cooperada. 
Sin embargo, el sector privado no siempre es "víctima" en los círculos de corrupción. Se habla también de un 'un triángulo de hierro' conformado por miembros de la clase política, la alta burocracia y grandes empresarios. En el marco de dicho esquema, éstos actúan empleando mecanismos concretos como la financiación de campañas políticas y de cabildeo tanto en el Congreso como ante los funcionarios públicos. (Misas: 2005)

Lo que da lugar a ese "triángulo de hierro" en Colombia se explica en buena medida por el fraccionamiento de los partidos, esto conlleva a la necesidad de generar acuerdos entre diferentes grupos, respecto a la administración y dirección de los entes estatales, es decir, el reparto por intereses del las instituciones del Estado.

Dado que la financiación de las campañas políticas dependen en gran medida de los aportes provenientes del sector privado, los electos funcionarios quedan supeditados a éste ó puede suceder también que sean sus mismos representantes quienes lleguen al poder, deslegitimando así las funciones de sus encargos populares a favor de intereses particulares como los grandes grupos económicos.

Esto se refleja con mayor claridad, por ejemplo, cuando se tramitan en el Congreso las reformas tributarias o se deciden las exoneraciones fiscales, que tienden a ser más benéficas para aquellos conglomerados con mayor poder económico y por ende de incidencia.

Los procesos legislativos llevados a cabo de esta manera, afectan la función la promulgación transparente de las leyes, entendiéndose que éstas deben atender el interés general, toda vez que se ponen al servicio de intereses privados. Ahora bien, esta presión realizada a través del lobby, no sólo se dirige sobre la rama legislativa sino también sobre la ejecutiva, garantizando el aprovechamiento de contactos personales de los grupos de interés con miembros del gobierno.

Este fenómeno corresponde a lo que se conoce como la Captura del Estado, término acuñado desde los organismos como el Banco Mundial BM y la Organización de Naciones Unidas ONU. Precisamente este concepto surgió en el Banco Mundial para caracterizar la preponderancia alcanzada por algunos empresarios que imponen sus intereses en el proceso de introducción al mercado mundial capitalista de los antiguos países pertenecientes a la Unión Soviética, con la intención de brindarse condiciones excepcionalmente ventajosas que favorezcan su entrada mediante el aprovechamiento de bienes y canales con la confianza de legislaciones convenientes a sus objetivos.

Lo descrito se evidencia con mayor claridad en las economías en transición y / o en formación. En el fondo se busca seguridad para entrar al mercado en estas economías (Hellman Jones, Kaufmann: 2000). Para América Latina la concepción de economías en formación es aplicable para unos sectores, con la debida contextualización, ha de entenderse que corresponde tanto a interés de actores empresariales que actúan en forma asociada como adicionalmente a los rigores que imponen la existencia de grupos ilegales con capacidad de intervenir igualmente los procesos políticos.

"Si bien casi todas las formas de corrupción tienden a modificar la manera en que se implementan las leyes, normas o reglamentos actuales en beneficio del que paga el soborno, la captura del Estado se refiere a los esfuerzos para influir en la manera en que se forman dichas leyes, normas o reglamentos. Los sobornos a los parlamentarios al "comprar" sus votos para que se sancionen determinadas leyes, los sobornos a funcionarios públicos para que aprueban normas o decretos favorables a intereses creados concretos o los sobornos a los jueces para que influyan en las decisiones de los tribunales son ejemplos clásicos de una corrupción a gran escala mediante la cual las empresas pueden obtener ventajas para ellas gracias a las distorsiones en el marco jurídico y reglamentario de la economía”(Hellman, Kaufmann, 2001). 
Por otra parte, Luís Jorge Garay (2008), define la captura del Estado como "la acción de individuos, grupos o firmas, en el sector público y privado, que influyen en la formación de leyes, regulaciones, decretos y otras políticas del gobierno, para su propio beneficio como resultado de provisiones ilícitas y no transparentes de beneficios privados otorgados a funcionarios públicos" (World Bank p. XV, 2000). Se dice que las empresas acceden a beneficios a la carte cuando adoptan prácticas para capturar el Estado, mediante pagos o dádivas no transparentes a funcionarios públicos (Hellman, Jones y Kaufmann, 2000). Cuando esto sucede, grupos y élites económicas manipulan la formulación de leyes, de manera que obtienen retribuciones económicas sostenidas y perdurables (Hellman y Kauffmann, 2001; Hellman, Jones, y Kaufmann, 2000b)".

Esta modalidad es particularmente frecuente en Colombia, pues como se dijo, el sistema político se encuentra fraccionado y a esto hay que sumarle los intereses ilegales e ilícitos que se imponen por la fuerza o por acuerdo directo con la clase dirigente.

\section{AHORA SOBRE LA COLUSIÓN}

Se entiende por colusión la sinergia nociva de participantes en un proceso de selección en detrimento del derecho de terceros a participar en condiciones de igualdad. El DRAE la define como pacto ilícito en detrimento de tercero y como vocablo tiene su origen en la expresión latina collusio-collusionis que se deriva del verbo colludo-colludere que significa "jugar juntos" (Sierra, 2003). La colusión afecta directamente el principio de libertad de empresa del que se deriva el derecho de libre competencia, por lo tanto, afectar la libre competencia significa necesariamente afectar la libertad de empresa.

En regímenes económicos de estirpe democrática la libertad de empresa es, junto con la propiedad privada, eje fundamental de los derechos económicos. No obstante, tan sencilla forma de describirlo dista mucho de ser sencilla en su práctica porque la democracia se enfrenta a un dilema del que muy difícilmente puede escabullirse, esto es, en temas de libertad de empresa se pone de manifiesto la tensión existente entre los dos rasgos característicos de la democracia: la libertad y la igualdad.

Un sistema democrático que privilegia la libertad sobre la igualdad obtendrá como resultado que quienes se muestren más hábiles para el desarrollo de las actividades económicas rápidamente tomen ventaja sobre quienes no lo son tanto y los sometan a sus condiciones en el espacio abierto que es el mercado, dando paso a fenómenos como los monopolios o los oligopolios; pero, si por el contrario, el sistema privilegia la igualdad sobre la libertad a través de la intervención coartará la libertad de quienes naturalmente cuentan con mayores habilidades para explotar el mercado a su favor y en su afán de distribuir igualitariamente las oportunidades lo único que logrará será nivelar a sus agentes económicos en función de los estándares más bajos porque es evidente que resulta más fácil exigirle al hábil que descienda al nivel del menos hábil que pedirle al incompetente que alcance los niveles de los más capaces. Ante ese dilema, los sistemas económicos contemporáneos han acudido a fórmulas intermedias de libertad vigilada, libertad con regulación o libertad con responsabilidad; al parecer, ninguna de estas fórmulas ha sido del todo exitosa.

En Colombia la libertad de empresa y su inherente libertad de competencia son principios de rango constitucional así como la dirección de la economía por parte del Estado y se consagran respectivamente en los Artículos 333 y 334. Así, el Artículo 333 dispone que la actividad económica y la iniciativa privada son libres y su único límite es el bien común; la libre competencia económica es un derecho de todos y, como se mencionó antes, supone responsabilidades. Por su parte, el Artículo 334 atribuye al Estado la dirección general de la economía y en virtud de tal atribución le impone la búsqueda de la distribución equitativa de las oportunidades. Nótese que el modelo colombiano hace una opción en favor de la libertad y, apelando 
al principio de responsabilidad, pretende alcanzar la igualdad.

La distancia entre estos dos principios democráticos permite la aparición de prácticas oligopólicas en tanto que, si bien los monopolios están prohibidos, son solo unos cuantos los que tienen el acceso pleno a los bienes del mercado y, acudiendo no en pocas ocasiones a las prácticas clientelistas descritas atrás, rápidamente toman ventaja de sus competidores débiles excluyéndolos del mercado o reduciéndoles ostensiblemente su campo de acción y por ende sus posibilidades de obtención de utilidad significativa.

La situación descrita anteriormente se asemeja a una carrera de caballos, si se entiende que la carrera de un solo caballo constituye un monopolio y que la carrera de varios caballos constituye una competencia justa y abierta. Empero, la mayor dificultad aparece cuando en la pista se ven compitiendo varios caballos pero los espectadores desconocen que todos los caballos pertenecen al mismo dueño. En sentido figurado, podríamos decir que la colusión consiste en el engaño de poner a correr varios caballos que privadamente representan un único interés particular.

Pero, ¿en qué consiste y cómo se caracteriza la colusión? A continuación presentaremos una aproximación descriptiva del fenómeno de la colusión como amenaza a los principios de inclusión, igualdad, libertad de empresa y libertad de competencia.

Una de las siete materias de la responsabilidad social, en el marco de la norma ISO 26000, son las Prácticas Justas de Operación, que se refieren a la conducta ética de una organización en sus transacciones con otras organizaciones. Incluyen las relaciones entre organizaciones y agencias gubernamentales, así como, entre organizaciones y sus socios, proveedores, contratistas, clientes, competidores, y las asociaciones de las cuales son miembros.

A su vez, los asuntos que se relacionan con ellas se presentan en los ámbitos de anticorrupción, participación responsable en la esfera pública, competencia justa, comportamiento socialmente responsable, relaciones con otras organizaciones y en el respeto a los derechos de la propiedad.

Nos detendremos en la competencia justa y abierta, de la que se espera estimule la innovación y la eficiencia, reduzca los costos de los productos y servicios, asegure que todas las organizaciones tengan las mismas oportunidades; también anima al desarrollo de productos o procesos nuevos y mejores y, en el largo plazo, mejora el crecimiento económico y el nivel de vida.Las conductas contrarias a esta competencia justa se deben a prácticas como la fijación de precios, licitaciones fraudulentas, fijación desleal de precios y la colusión (que puede ser expresa o tácita).

De acuerdo con Quintana (2008), la colusión explícita se presenta cuando las empresas miembros de un oligopolio ${ }^{1}$ tienen comunicación y/o contacto efectivo entre ellas que les permite coordinar su comportamiento a fin de dejar de competir. En términos legales este comportamiento se califica como acuerdos o prácticas concertadas y se denomina genéricamente como carteles.

Sin embargo, aunque no siempre existe la posibilidad de comunicación o contacto directo entre las empresas, éstas pueden ajustar su comportamiento al de sus rivales; debido a las particulares condiciones del mercado que les permiten detectar oportunamente la desviación del comportamiento esperado y, además, hacen creíble que aplicarán medidas de represalia frente a las desviaciones que se identifiquen. Bajo estas circunstancias se presenta la colusión tácita.

Las conductas colusorias se dan tanto en las relaciones empresariales entre el sector privado, como en las relaciones que las empresas entablan con el sector público a través de la contratación estatal. La colusión, como forma

1 El oligopolio se define como el mercado en el que unas pocas empresas llevan a cabo la producción de un bien o servicio, lo que crea un alto grado de interdependencia entre las decisiones de las mismas. 
de distorsión del mercado puede derivar en corrupción ${ }^{2}$. Aunque esta modalidad de corrupción, se da también en el sector privado, preocupa su ocurrencia en el público, pues esto genera sobrecostos para el Estado y la consecuente ineficiencia tanto en la prestación de servicios como en la asignación equitativa de recursos. Sobre la última recae el interés de este artículo. En cualquier, caso el principal y directamente afectado siempre será el consumidor o usuario final, dada las limitadas posibilidades de escoger a sus proveedores y los altos costos que esto traduce.

En el Estado, la colusión se presenta vía contratación a través de licitaciones públicas y cada vez en mayor medida en la contratación directa. La administración destina buena parte de sus recursos a la adquisición de bienes y servicios, las utilidades percibidas por los proveedores son atractivas, pues por lo general se trata de compras a gran escala; sin embargo, la adjudicación no siempre se realiza con la eficiencia y transparencia necesarias, dando lugar a la corrupción y a la formación de prácticas contrarias a la libre competencia.

Para el caso colombiano, es innegable que persiste la corrupción en la contratación estatal, así lo evidencian varios informes. Por ejemplo, la Tercera Encuesta Nacional sobre Prácticas contra el Soborno en Empresas Colombianas, indica que el $94 \%$ de los empresarios -un punto porcentual por encima de los resultados del año 2010- considera que se ofrecen sobornos en el entorno de los negocios. Esto demuestra que la generación y afianzamiento de una cultura de prevención de esta práctica desde las empresas aún sigue siendo incipiente en cuanto a la aplicación de buenas prácticas. Esto lo corrobora el hecho de que el $58 \%$ de los empresarios no cuentan con ningún canal para denunciar casos de soborno. (Transparencia por Colombia - Universidad Externado, 2012).

2 De acuerdo con Transparencia Internacional, corrupción es el mal uso del poder encomendado para obtener beneficios privados.
Por su parte, las encuestas del Banco Mundial y de Confecámaras muestran que en las licitaciones públicas pueden gestarse procesos de "selección adversa" porque vastos sectores empresariales se han marginado de las oportunidades de trabajar con el Estado debido a la poca transparencia en los procesos licitatorios, con lo cual se ha restringido la competencia por los negocios estatales. Al indagar sobre los criterios de rechazo básicos para su no participación, cerca de la mitad de los empresarios encuestados consideraron, en orden de importancia:

\section{i) La competencia injusta,}

ii) La complejidad en el proceso licitatorio y

iii) Tener contactos personales dentro de la entidad contratante, aspectos que ratifican la existencia de un creciente nivel de desconfianza respecto a la capacidad del Gobierno para establecer reglas claras de participación para las entidades y los oferentes, y corregir las deficiencias existentes en la mayoría de los procesos de contratación del Estado. (En documento Conpes, 2003)

Ahora bien, cuando se presenta colusión en licitaciones, esta práctica puede afectar cualquiera de las fases contractuales: i) La precontractual. Es el caso de las empresas que deciden que una de ellas se abstendrá de competir, o, por parte de los funcionarios públicos a cargo del proceso que diseñan los pliegos "a la medida" de uno de los oferentes, para que sólo éste se encuentre en condiciones de cumplir. ii) Durante la presentación de las ofertas. Es el caso de los oferentes que acuerdan entre ellos quién ganará la licitación, retirándose los demás o allegando propuestas con parámetros inaceptables para la administración. iii) Tras la adjudicación de la licitación, pueden realizarse acuerdos que se mantengan vigentes, como la promesa de contratar con quienes "perdieron", en calidad de subcontratistas.

Al coludirse los competidores, se reduce la oferta disponible para que el Estado compre en mejores condiciones de mercado y se produce un desperdicio de recursos. El efecto anterior es socialmente indeseable y contrario al propósito 
de obtener más, gastando menos, es decir, eficiencia óptima.

\section{ESTATUTO ANTICORRUPCIÓN: UN MARCO REGULATORIO PARA LA ACCIÓN}

Ya se ha expuesto cómo el sector privado puede ser sujeto activo o pasivo tanto en el fenómeno de la corrupción como en el de la colusión. Puede tener un rol en el que despliega una conducta corrupta, o uno en el que su acceso al mercado en condiciones de equidad se ve limitado por pretensiones extra legales de otros.

Colombia, país de leyes por excelencia, cuenta con diferentes instrumentos normativos para combatir la corrupción; entre ellos la Ley 1474 de 2011, mejor conocida como Estatuto Anticorrupción.

Contrario a la Ley 190 de 1995 (primer Estatuto Anticorrupción), la de 2011 contempla directamente al sector privado; lo cual realza la necesidad de su compromiso social en aras de lograr una sociedad más justa y libre de corrupción.

La Ley 1474, consagra la responsabilidad de las personas jurídicas en general, como sujetos disciplinables -artículo 44-, a sus representantes legales y miembros de juntas directivas, en lo cual lo hace armónico con los deberes de éstos establecidos por la Ley 222 de 1995 por la cual se modifica el libro segundo del Código de Comercio y a sus responsabilidades, artículos 23 y 24 .

Otros artículos con implicaciones respecto al sector privado son: el artículo 1, que consagra la inhabilidad para contratar de quienes incurran en actos de corrupción; entre ellos las sociedades (excepto las anónimas abiertas) de las que sean socias las personas naturales inhabilitadas.

También contempla límites a la financiación de campañas políticas, que como se anotó supeditan la transparencia de las elecciones y de los funcionarios de elección popular. El tope establecido es de $2.5 \%$ de las sumas máximas invertidas por los candidatos en sus campañas electorales. Quienes lo superen, quedarán inhabilitados para contratar con entidades del nivel en el que fue elegido el candidato.

Por su parte, el artículo 3, establece la prohibición para que ex servidores públicos gestionen intereses privados, hasta por los dos años siguientes a la dejación del cargo, respecto a asuntos relacionados con funciones propias de la labor que desempeñada y de la entidad en la cual prestó sus servicios. Esto es comúnmente conocido como "puerta giratoria".

Así se le conoce a la práctica de funcionarios que saltan del sector privado al público, o viceversa. Aunque esto siempre ha existido en Colombia, la controversia se ha aumentado en razón a la numerosa cantidad de funcionarios que pasan de ejercer cargos públicos a gestionar intereses en el sector privado.

Respecto a la reglamentación del nuevo Estatuto Anticorrupción, este punto ha desatado un fuerte debate. Por un lado, es indispensable reglamentar el conflicto de intereses que pueden tener ex funcionarios de cierta jerarquía con acceso a información privilegiada y por las funciones que desempeñaron. Por otro lado, también hay que considerar el tiempo que debe esperar un funcionario desde que renuncia a su cargo para rehacer su vida en el sector privado. (Revista Semana: 2011).

Por su parte, el artículo 16 de la mencionada Ley 1474 de 2011, estipula sanciones frente a la corrupción privada. La pena será entre 4 y 8 años por ofrecer o por solicitar dádivas o cualquier otro beneficio no justificado para obtener favorecimiento de intereses propios o de un tercero. En caso de producirse un detrimento económico de la entidad (sociedad, asociación o fundación), la pena se incrementará de 6 a 10 años.

Por su parte, el artículo 28, contempla sanciones al ejercicio indebido de influencias de un particular sobre un servidor público con pena de 4 a 8 años. 
No obstante, a pesar que el lobby o cabildeo han sido factores generadores de corrupción por su inadecuada utilización, el Estatuto apenas dedica el artículo 61 para referirse al tema y se limita a señalar que la autoridad competente podrá requerir en cualquier momento información o antecedentes en caso de existir al menos prueba sumaria de la comisión de un delito o falta disciplinaria. Vale decir que es necesario profundizar sobre el tema y establecer una mejor y más clara reglamentación.

El artículo 30 contempla el soborno transnacional, como dar $\mathrm{u}$ ofrecer a un servidor público extranjero dinero $u$ otra utilidad para omitir o retardar cualquier acto relacionado con una transacción económica o comercial.

Finalmente, y en relación directa con la colusión, el artículo 27 castiga los acuerdos restrictivos de la competencia, cuando se busque alterar ilícitamente los procesos de licitación pública, con pena de prisión de 6 a 12 años.

Desde esta perspectiva, el Estatuto establece un tipo penal específico para los acuerdos restrictivos de la competencia en la contratación estatal. Sin embargo, esta tipificación no incluye las conductas entre el mismo sector privado que puedan afectar directa o indirectamente la dinámica del mercado y se centraron esfuerzos en combatir los perjuicios más evidentes de la colusión, el erario público.

Ahora bien, cabe decir que dicho delito de acuerdos restrictivos de la competencia es establecido como un delito de mera conducta. El problema entonces radica en la carga probatoria que debe asumir el estado en contra de la persona o grupo de personas que pretenda acusar de la comisión de dicho delito.

La carga del onus probandi, en muchos casos resulta imposible de conseguir toda vez que las garantías procesales del sistema penal acusatorio protegen al investigado, indagado y/o acusado, y principios fundamentales como el indubio pro reo impiden que se realice una responsabilidad objetiva ya que esta se encuentra totalmente prescrita en nuestro ordenamiento jurídico.

\section{COMPROMISOS INTERNACIONALES: EL RETO DE COLOMBIA}

Para comenzar, en Colombia por medio de la Ley 412 de 1997, se aprobó la Convención Interamericana contra la Corrupción-CICC-, así mismo se obliga a cumplir con el mecanismo de seguimiento de la Implementación de la Convención el cual consta de un cuestionario que debe responder el Estado Colombiano y un informe con recomendaciones dado por el comité de expertos del Mecanismo de Seguimiento de la Implementación de la Convención Interamericana contra la Corrupción (MESICIC).

La CICC tiene como propósitos": "Promover y fortalecer el desarrollo, por cada uno de los Estados Partes, de los mecanismos necesarios para prevenir, detectar, sancionar y erradicar la corrupción; y, promover, facilitar y regular, la cooperación entre los Estados partes a fin de asegurar la eficacia de las medidas y acciones para prevenir, detectar, sancionar y erradicar los actos de corrupción en el ejercicio de las funciones públicas y los actos de corrupción específicamente vinculados con tal ejercicio".

Luego, por medio de la Ley 970 de 2005, Colombia aprobó la Convención de las Naciones Unidas contra la Corrupción (de 2003). Esta Convención ofrece una posibilidad extraordinaria de promover una respuesta mundial al vasto problema mundial de la corrupción. Nació como un compromiso de la Comunidad Internacional para combatir la corrupción y como un deber de cooperación por parte de los países para combatirla, prevenirla y sancionarla. En la Convención es visible el hecho de que la corrupción es un factor que incide en la pobreza y en el bajo rendimiento de los

3 http://www.oas.org/juridico/spanish/tratados/b-58. html 
Estados, de ahí la importancia de la Convención en adoptar medidas preventivas, tipificar las formas de corrupción y devolver los bienes procedentes de la corrupción.

Por último, en diciembre de 1997 la Organización para la Cooperación y el Desarrollo OCDE, ratificó la Convención Contra el Soborno Transnacional buscando penalizar a quienes paguen $u$ ofrezcan recompensas a oficiales extranjeros en las transacciones internacionales. Esto guarda estrecha relación con el citado artículo 30 del Estatuto Anticorrupción.

En diciembre de 2011, en el marco de la visita de alto nivel realizada por una misión de la OCDE, Colombia recibió la carta de invitación a adherir a la 'Declaración sobre Inversión Internacional y Empresas Multinacionales' de ese organismo.

Así, Colombia se convirtió en el país número 43 que es invitado a suscribir la Declaración, considerada uno de los instrumentos legales más importantes de la OCDE, lo cual le da derecho a participar en el Comité de Inversión de la Organización.

En la práctica, lo que hace Colombia al adherir, es comprometerse a dar un trato no discriminatorio a los inversionistas extranjeros de los otros 42 países signatarios y a promover una conducta empresarial responsable, por parte de las empresas multinacionales que operan en el país y las colombianas que tienen asiento en el extranjero.

Adicionalmente, Colombia, después de revisar los estándares en materia de combate a la corrupción, fue invitada por la OCDE a firmar la Convención para Combatir el Cohecho de Servidores Públicos Extranjeros en Transacciones Comerciales Internacionales, instrumento introducido a la normatividad nacional a través de la Ley 1573 de 2012.

Respecto al ingreso como miembro pleno, el 19 septiembre de 2013 los 34 miembros de la Organización para la Cooperación y el Desarrollo
Económico (OCDE) aprobaron la hoja de ruta para la adhesión de Colombia a este grupo, en ese momento el secretario general de la Organización, Ángel Gurría, anunció el comienzo del proceso para la inclusión del país. Tras esta formalización, el primer paso para Colombia consiste en la presentación ante la OCDE de un memorándum inicial en el que debe establecer su posición frente a 250 instrumentos de carácter legal que tiene la organización. Este documento será revisado por expertos del organismo, para luego ser evaluado por los comités del mismo. La decisión final sobre el ingreso o no será adoptada de manera conjunta por los 34 integrantes de la Organización.

\section{LO VOLUNTARIO: PACTO GLOBAL}

La iniciativa de Pacto Global fue promovida en el seno de las Naciones Unidas en el año 2000. Para ese entonces contaba con 9 principios relacionados con las áreas de derechos humanos, estándares laborales, medio ambiente.

Es en el 2004 cuando se observa la necesidad de incluir el Principio 10: Anticorrupción, toda vez que constituye un elemento transversal para el logro y sostenibilidad de los 9 primeros.

El propósito de este Principio 10 es comprometer a los participantes del Pacto Global, no solamente a evitar el soborno, la extorsión y otras formas de corrupción, sino también a desarrollar políticas y programas concretas para abordar el tema de la corrupción. Se desafía a las empresas se unan a los gobiernos, a las agencias de la ONU y a la sociedad civil para crear una economía global más transparente y libre de corrupción. (Global Compact).

Ya sean los riesgos legales, los riesgos de reputación o los costos financieros, la creciente presión de la sociedad y de un consumo que busca ser responsable, han hecho que los empresarios generen conciencia de la necesidad de un actuar ético y transparente. 
Ahora las empresas se preocupan no sólo por el giro específico de sus negocios, sino por la estabilidad social y en el crecimiento económico de las comunidades locales. Esto debido a que unas condiciones deficientes de desarrollo, socavan sus propias posibilidades de extender sus mercado y crear cadenas completas de valor.

Además, más allá de los beneficios económicos, el sector privado entiende cada vez con mayor precisión que es insostenible ejecutar sus operaciones en entornos con condiciones precarias; esto genera riesgos económicos y sociales, en especial cuando se trata de escenarios donde se mezclan insuficiencias sociales con factores de violencia. Por eso, la comunidad empresarial puede y debe tener un rol activo que logre reducir y erradicar la corrupción.

En tal sentido, el Pacto Global ha establecido tres niveles para la implementación del Principio 10 en las organizaciones. Debe partirse de la acción interna, como paso básico de la empresa, en aras de implementar políticas y programas anticorrupción en sus negocios y operaciones. Acciones tales como liderazgo, adopción de códigos de ética, adopción de mecanismo de informe internos y entrenamiento y liderazgo, forman parte de esta fase.

Respecto a la acción externa, se pretende que informe sobre su trabajo contra la corrupción a través del mecanismo de comunicación establecido por el Pacto, así como que comparta con otras organizaciones el desarrollo de buenas prácticas. Se trata entonces de fomentar una cultura de transparencia.

Finalmente, un tercer paso es la acción colectiva. Consiste en identificar prácticas de corrupción que no sólo afectan a la empresa en particular sino que se repiten en otras empresas y que en consecuencia es más efectivo combatirlas aunando esfuerzos; por lo general esto se manifiesta cuando existe una cultura local que promueve este tipo de prácticas corruptas. Entonces, es necesario generar conciencia colectiva y adoptar medidas de este tipo al respecto y que además garantice la libre competencia y la realización transparente de los negocios.

Se observa entonces que si bien Pacto Global es una iniciativa de adhesión voluntaria, resulta un mecanismo efectivo y eficaz para alcanzar el propósito de sus principios, en este caso de Anticorrupción, en aras del fortalecimiento de la conciencia empresarial en torno a su rol en la sociedad y bajo el precepto de la corresponsabilidad en la lucha contra la corrupción entre el sector privado y el Estado. No obstante, aún falta buena parte del camino por recorrer, pues es imperativo establecer compromisos que aseguren una postura de cero tolerancia a la corrupción en el entorno de las transacciones comerciales.

Este punto es fundamental porque recalca la responsabilidad compartida entre las partes $y$ la necesidad de promover una cultura nacional por la transparencia y el rechazo social contra estos delitos que menoscaban la economía y perjudican a toda la sociedad colombiana. Así se dijo en el Documento Construcción Colectiva de lineamientos para la reglamentación del Estatuto en relación al sector privado; proyecto ejecutado por la corporación Transparencia por Colombia, el Ministerio del Interior y la Asociación Nacional de Empresarios -ANDI-.

\section{PARA CONCLUIR}

En una sociedad cada vez más basada en el desarrollo de mercados, es indiscutible el rol del sector privado como agente transformador de la cultura que enmarca el juego de oportunidades.

Si bien son conocidas las consecuencias legales derivadas de ejecutar actos de corrupción, el empresariado considera otros factores que también le motivan, quizá con más fuerza que los mismos jurídicos, a llevar a cabo sus actuaciones en un marco de transparencia.

Es importante mencionar que la restricción de las oportunidades comerciales y las operaciones se considera que como uno de los mecanismos 
más eficaces para motivar a las empresas para hacer frente a la corrupción; aunque paralelamente la pena privativa de la libertad es un elemento predominante de disuasión.

Así mismo, otros mecanismos como los índices de corrupción, que eduquen y concienticen a la opinión pública en la necesidad de realizar un consumo responsable, que considere o privilegie aquellas empresas que demuestren su lucha contra este flagelo y que castigue a las que lo promuevan, deben ser implementados y socializados de manera más efectiva.

Más que por imposición legal, de lo que se trata es de fomentar una cultura de legalidad y de ética, en donde prime el bien común y se entienda que la corrupción impacta directamente la calidad de vida y las posibilidades de desarrollo y sostenibilidad de la humanidad.

Esto mismo aplica frente a la colusión, que representa una práctica corrupta enmarcada principalmente en sistemas económicos en los que se privilegia el principio de libertad sobre el principio de igualdad, dando paso a sistemas oligopólicos que se quedan cortos en materia de control y no logran el propósito de garantizar el acceso a las oportunidades económicas en condiciones de igualdad. Los oligopolios son un ámbito favorable para la práctica de la colusión porque el poder económico se concentra en pocas personas y el poder político (legislativo y administrativo) suele plegarse a la capacidad de corrupción de los grupos económicos.

La precariedad de las normas y la falta de neutralidad de las leyes sumadas al clientelismo y al corporativismo como formas de corrupción, favorecen la práctica de la colusión e impiden el control ciudadano y la acción de las autoridades. La responsabilidad de quienes ejercen prácticas colusivas no debe agotarse en la acción coercitiva del derecho sino que debe implicar un fuerte juicio ético y social. Las categorías jurídicas se quedan cortas aunque tengan un gran despliegue normativo porque la capacidad del estado para aplicarlas muchas veces sucumbe ante el auge de la práctica corrupta.

Entonces, un buen régimen de control sobre las actuaciones de los particulares y las autoridades en esta materia debe comenzar por la evaluación de su nivel de responsabilidad social. Los sujetos involucrados en las relaciones Estado-particulares deben tener siempre presente que su actividad entraña una profunda responsabilidad frente al estado, frente a la sociedad y frente a ellos mismos, de tal modo que corresponsablemente deben adoptar medidas para erradicar la práctica de la colusión.

\section{REFERENCIAS}

Banco Mundial, Corporación Financiera Internacional. Indicador Doing Bussines. 2014. Disponible en: http://espanol.doingbusiness.org/

Congreso de la República. Ley 1474 de 2011. Estatuto Anticorrupción. Publicada en el Diario Oficial No. 48.128 de 12 de julio de 201.

Congreso de la República. Ley 1573 de 2012. Por medio de la cual se aprueba la Convención para combatir el cohecho de servidores públicos extranjeros en transacciones comerciales internacionales. Publicada en el Diario Oficial No. 48.510 de 2 de agosto de 2012.

Corporación Transparencia por Colombia, Ministerio del Interior, ANDI. Construcción Colectiva, lineamientos para la reglamentación del Estatuto Anticorrupción en relación al sector privado. Bogotá. 2012

Riesgos de incidencia indebida de intereses particulares en la formación de las leyes. Bogotá. 2005

Hechos que rompen el círculo vicioso de la Corrupción, Informe Anual. Editora Capítulo Transparencia Internacional, Bogotá. 2003. 
Universidad Externado de Colombia, Tercera Encuesta Nacional sobre Prácticas contra el Soborno en Empresas Colombianas, Colección Cuadernos de Transparencia No. 20. Bogotá. 2012.

Consejo Nacional de Política Económica y Social República de Colombia Departamento Nacional de Planeación. Documento Conpes No. 3249. Octubre de 2003.

De Speville Bertrand. Superando la Corrupción. Los Elementos esenciales para combatirla. Editorial Planeta, 2011.

Garay Luis Jorge. (Noviembre 2009). La política es un medio eficiente para infiltrar el Estado. Revista Semana, Entrevista de Gustavo Gómez. Disponible en: http://www.semana.com/nacion/ articulo/la-politica-medio-eficiente-para-infiltrarestado/109883-3

Garay Salamanca Luis Jorge y otros. La captura y reconfiguración cooptada del Estado en Colombia. Editora Fundación Método, Transparencia por Colombia, Fundación Avina. Bogotá, 2008

Global Compact y otros (2005). Los negocios contra la corrupción. Un marco para la acción. Londres.

Transparencia Internacional Cambridge University. (2009). Informe Global de la Corrupción 2009. Corrupción y sector privado. Disponible en: http://www.cgu.gov.br/conferenciabrocde/ arquivos/Espanol-Informe-Global-de-lacorrupcion-2009.pdf

Hellman, Joel y Daniel Kaufmann. La captura del Estado en las economías en transición. Disponible en: http://www.imf.org/external/pubs/ $\mathrm{ft} /$ fandd/spa/2001/09/pdf/hellman.pdf

Hellman, Joel. "Capture al Estado, Capture el día" Captura del Estado, corrupción e influencia en la Transición. Banco Mundial. Disponible en: http://www.democraciacdh.uchile.cl/media/
publicaciones/syllabus/16Hellman_Jones_ Kaufmann.pdf. 2010.

Humboldt-Viadrina School of Governance. (2012) Motivating Business to Counter Corruption. Berlín.

Instituto Banco Mundial (2002). Corrupción, desempeño institucional, y gobernabilidad: Desarrollando una estrategia anti-corrupción para Colombia. Resumen Ejecutivo, Washington.

Misas, G. (2005) La lucha anticorrupción en Colombia, teoría, prácticas y estrategias. Bogotá D.C: Contraloría General de la República.

Organización de las Naciones Unidas. (2005) Convención de las Naciones Unidas contra la Corrupción. Disponible en: http://www.unodc. org/pdf/crime/convention_corruption/signing/ Convention-s.pdf

Organización de Estados Americanos (1996). Convención Interamericana Contra la Corrupción. http://www.oas.org/juridico/spanish/tratados/b-58.html.

Organización para la Cooperación y el Desarrollo Económicos OCDE. http://www.oecd.org/.

Querubín, Londoño Rodrigo. (2005)La Lucha Anticorrupción y la Ética Pública y Privada. Bogotá: Editorial Carrera $7^{\mathrm{a}}$ Ltda.

Quintana Sánchez, Eduardo. (2008) Tratamiento de la colusión tácita en el Perú: marchas y contramarchas. Rev. Derecho Competencia. Bogotá (Colombia), vol. $4 \mathrm{~N}^{\circ} 4,119-189$, enero diciembre. 119 - $189 \mathrm{p}$.

Sierra García, Jaime. (2003) Diccionario Jurídico. Librería Jurídica Sánchez R. Ltda. Cuarta Edición, Bogotá.

Universidad de Antioquia (2002) El Impacto de la Corrupción sobre el crecimiento económico colombiano, 1990 - 1999. Medellín. 